\title{
Управление стратегическими изменениями через реформы, осушествляемые ПСОСО: перспективы сотрудничества США и Армении по программе «Умная сила»
}

\author{
Хайк Котанджян*
}

Образование есть систематический процесс формирования фундаментальной способности думать аналитически, который включает использование как базовых, так и специализированных знаний. Поэтому в вооруженных силах ведущих стран мира сфера военного образования и менеджмента персонала считается первостепенным фактором для обеспечения эффективности системы обороны и безопасности и боевой способности вооруженных сил.

Реформы образования в сфере обороны являются существенной частью общих реформ в секторе обороны и безопасности в Армении, которые направлены как на укрепление доверия к Вооруженным силам Армении и на усиление их подотчетности, так и ко всей системе национальной безопасности. Значение образования в сфере обороны существенно выросло в последние годы вследствие введения новых совершенных систем вооружения. Современные военные стандарты поднимают уровень требований как к солдатам, так и к офицерам, и профессиональное военное образование является одним из наиболее важных инструментов для подготовки высококвалифицированного личного состава, который будет в состоянии выполнять разнообразные задачи в быстроменяющейся атмосфере на современном поле боя.

Причины и сущность этих инноваций не только проистекают из динамики подсистемы жесткой силы, но и требуют принятия фундаментально новой ориентации мышления в сфере безопасности, которая не основывается исключительно на оценке угроз и предполагаемой жесткой реакции, как было в прошлом. В течение последнего десятилетия, после саммита НАТО в Праге, Армения применяла сравнительный анализ и инновационные решения для плавного поворота мышления в сфере обороны в сторону целевого подхода, который сочетает как мягкие, так и жесткие измерения безопасности в одну целостную систему политики безопасности, основанную на концепции «умной силы». Другим важным измерением этих улучшений является постепенный переход от устаревшего «аппаратного» режима сталинского типа управления министерством обороны к современному руководству и менеджерской культуре, для которых характерно перераспределение власти между институциями, формирующими политику в сфере обороны, и воен-

Доктор Хайк Котанджян, генерал-майор Вооруженных сил Армении, основатель и руководитель Института национальных стратегических исследований армянского министерства обороны. Он был приглашенным профессором в Институте национальных стратегических исследований при Национальном университете обороны США и членом рабочей группы экспертов комиссии Организации Договора о Коллективной Безопасности. 
ными органами управления, и делегирование прав и обязанностей более низким слоям иерархии.

В Соединенных Штатах система профессионального военного образования (ПВО) должна отвечать определенным основным требованиям, а именно, она должна быть комплексной, систематической, последовательной, реалистической, эффективной и непротиворечивой в смысле концепций, терминов, целей, проблем и возможностей. Я знаком с системой в США благодаря моей работе в течение пяти с половиной лет в качестве военного, военно-воздушного и военно-морского атташе, и благодаря академическим должностям, которые я занимал в Военном институте изучения языков в Сан-Антонио, в программе по национальной безопасности гарвардского университета, в Национальном университете обороны, в корпорации RAND и в Центре исследований по вопросам безопасности им. Маршалла. ПВО создает постоянную нагрузку на ум, волю и тело, уделяя большое внимание физической форме и ее важной роли при выполнении служебных обязанностей во всех категориях личного состава.

\section{Ранние этапы развития сектора образования в сфере обороны в Армении}

Формирование вооруженных сил Армении совпало с тем, что, возможно, было наиболее трудным и стрессовым периодом в современной армянской истории: переход от советского тоталитарного режима к независимой национальной государственности на основе ценностей либеральной демократии. Составление проекта основного устройства вооруженных сил Армении одновременно с установлением независимой армянской государственности стало вызовом, к которому надо было подходить очень внимательно, имея в виду крайнюю неопределенность, которой характеризовалась динамика пост-советской системы глобальной, региональной и национальной безопасности. Для меня было большой ответственностью поручение руководства нового министерства обороны разработать «Основы военной политики Республики Армения», которые были опубликованы в 1992 году в качестве первого военно-политического национального документа, определяющего доктринальное содержание и стратегический калибр независимой Армении. ${ }^{1}$ Этот документ стал начальной рамкой, определяющий развитие национальной системы военного образования.

Дополнительные затруднения для Армении проистекали из конфликта в Нагорном Карабахе, а так же и из-за блокады, осуществляемой Азербайджаном и Турцией. В те трудные дни ряды армянской армии по необходимости заполнялись многими патриотами с недостаточным военным опытом и образованием. Надо подчеркнуть, что в советское время Армения была единственной из республик без

1 Доктор Хайк Котанджян, “Основы военной политики Республики Армения: Военнополитический аспект национальной безопасности” (на Армянском) (Ереван: Департамент Военной политики, Минобороны Армении, 1992). 
какого бы то ни было военного учебного заведения, которое могло бы стать отправным пунктом для развития сектора образования в сфере обороны после распада СССР.

Между тем руководство Армении полностью осознавало важность образования в сфере обороны в общем процессе строительства национальных вооруженных сил. Министерство обороны инициировало процесс учреждения образовательных институций в сфере обороны в 1994 году. Во-первых, в июне и сентябре 1994 года были учреждены два училища для младших офицеров. Одновременно министерство обороны создало специальную военную среднюю школу, чья основная миссия состояла в подготовке молодого поколения к будущей службе в вооруженных силах.

В тот период военное политическое руководство Армении очень хорошо понимало трудности, с которыми сталкивался процесс создания функциональной системы образования в сфере обороны. Одной из проблем являлась нехватка квалифицированных специалистов в разных областях, в частности, касающихся подготовки высших офицеров для армянской армии. Один из срочных шагов, предпринятых для преодоления этого препятствия, было развитие сотрудничества в военном образовании с Россией, стратегическим союзником Армении, которая в тот период времени тоже объявила поворот в сторону демократии.

Российско-армянское сотрудничество в области образования в сфере обороны основывалось на Договоре о дружбе и взаимопомощи между двумя государствами от 1997 года. ${ }^{2}$ Одновременно были предприняты шаги к установлению контактов и со странами-членами НАТО. В 1994 году Армения присоединилась к программе НАТО «Партнерство ради мира», которая была создана, чтобы позволить двухстороннее сотрудничество между индивидуальными государствами и НАТО. Многими эта программа рассматривалась как платформа, предназначенная для сдвига бывших советских республик в сторону НАТО. Отличительной чертой программы являлось то, что она предоставляла Армении возможность укреплять индивидуальные отношения с НАТО с целью увеличить стабильность и укрепить отношения в сфере безопасности. Позже Армения присоединилась и к Процессу Планирования и Оценки (ППО) ПРМ, который считался основным инструментом в рамках сотрудничества по вопросам безопасности. В духе ПРМ, в результате интенсивных двухсторонних консультаций Армения дала старт инициативе военного сотрудничества в западном стиле, первоначально работая с Грецией в качестве первого партнера из членов НАТО. В 1996 году Армения и Греция подписали договор о сотрудничестве в военной сфере и позже продолжили это сотрудничество, заключив в 1998 году соглашение о сотрудничестве в сфере образования и квалификации, которое позволило армянским офицерам получать подготовку в военнообразовательных институтах Греции. В то время для меня в качестве начальника отдела международных отношений и военного сотрудничества министерства обо-

2 Полный текст соглашения доступен на http://www.parliament.am/library/erkoxm/19961998/73.pdf (на армянском). 
роны Армении было очень интересным переживанием инициировать, балансировать и управлять - от имени министра обороны Армении - такой тип сотрудничества в сфере профессионального военного образования как с западными, так и с постсоветскими партнерами. Таким образом, к концу 1990-х Армения преодолела множество проблем и создала работающий механизм для своей системы образования в сфере обороны на основе ряда стратегических, ориентированных на будущее развитие реформ в профессиональном военном образовании, реализованных в рамках Программы Совершенствования Образования в Сфере Обороны (ПСОСО).

\section{Текущий этап реформ в ПВО}

К началу двадцать первого века, Армения завершила первый этап строительства своей системы образования в сфере обороны, создав функционирующую модель, которая отвечала минимальным требованиям вооруженных сил. Между тем, было очевидно, что система оставалась основанной на старых советских традициях, и поэтому не соответствовала новым вызовам в секторе обороны двадцать первого века. Другой основной проблемой для вооруженных сил Армении, было то, что несмотря на наличие двух институтов военного образования, у Армении не было потенциала давать образование высшим офицерам, и приходилось посылать нарастающее число офицеров в иностранные военные институты (в основном в России). Другим препятствием на пути развития системы образования в сфере обороны в Армении, была увеличивающаяся пропасть между гражданским и военным образованием. С середины 1990-х, Армения активно начала реформировать гражданское образование, прилагая усилия направленные на введение в Армении европейской модели среднего и высшего образования. Более известная как Болонский процесс, эта модель формировала высшее образование на трех уровнях (бакалаврские, магистерские и докторские программы). В начале 2000-х почти все армянские государственные и частные университеты предлагали обучение для получения степени бакалавра и магистра. Система образования в сфере обороны, однако, оставалась в стороне от этих реформ и продолжала давать дипломы и частично бакалаврские степени, без магистерской степени в области военного искусства или военных наук.

Руководство министерства обороны было полностью в курсе ситуации и искало пути разрешения этой проблемы. Основные направления политики по этому вопросу включали установление отношений в сфере военного образования с НАТО и планирование учреждения институтов образования в сфере обороны, имеющие потенциал готовить высших офицеров, а так же предпринятие необходимых шагов для создания межведомственного института для образования в сфере обороны, по образу Национального университета обороны (НУО) США. Краеугольным камнем в этом процессе стало подписание в 2005 году первого Индивидуального плана действий по партнерству (ИПДП) между Арменией и 
HАTO. ${ }^{3}$ Чтобы лучше ознакомиться с точкой зрения США на содержание ИПДП, разработанного НАТО после саммита в 2002 году в Праге, в 2003 году руководство МО отправило меня в НУО США для прохождения курса штабных офицеров НАТО. Получив ценную информацию из первых рук в Вашингтоне и Брюсселе, руководство Армении приняло решение применить ИПДП НАТО.

В соответствии с требованиями ИПДП, необходимо разработать и принять такие стратегические документы в сфере безопасности, как Стратегию национальной безопасности и Военную доктрину. Применение методологии США для межведомственной разработки Стратегии национальной безопасности и сравнительный анализ с российскими методологическими принципами, были осуществлены во время моей работы в Институте исследований по вопросам национальной безопасности в Национальном университете обороны США в 2003-2004 году, как и исследования для моей монографии Основные положения для разработки стратегии национальной безопасности Армении в контексте региональной архитекmуры безопасности. ${ }^{4}$ Была сформирована межведомственная комиссия под эгидой Сержа Саргсяна, бывшего тогда министром обороны, а сейчас действующий президент Армении, которая под моим научным руководством создала проект первой армянской Стратегии национальной безопасности на основе методологии, полученной от НУО. Специальная методическая помощь, которую оказала на этапе исследований и разработки этого творческого процесса в 2005-2006 году доктор Тереза Сабонис-Хелф, профессор в национальном стратегическом военном колледже США, была исключительно полезной для развития нового подхода к мышлению в сфере безопасности в Армении. Стратегия национальной безопасности Армении служит методологической и интеллектуальной основой для утверждения ориентированного на западную концепцию «умной силы» мышления в сфере обороны и для осуществления стратегических реформ в системе образования в сфере обороны.

ИПДП так же позволил Армении в полной мере включить экспертов НАТО в процесс проведения реформ в системе образования в сфере обороны. Как писал по этому вопросу Джон Бери, один из руководителей процесса ПСОСО:

Рабочая группа Консорциума НАТО фокусировала свои усилия на трех элементах ПВО стран-партнеров: (1) учебные программы, которые отвечают потребностям в образовании и квалификации современных вооруженных сил; (2) методы преподавания и учебы, которые соответствуют лучшим практикам, применяемым в западных институтах образования и квалификации в сфере обороны; (3) усовершенствование преподавателей и институций путем применения системы наставничества на определенный период. Для каждой участвующей страны-партнера (Армения, Азербайджан, Грузия, Казахстан и Молдова) рабочая группа начала выполнение

3 С обязательствами Армении, проистекающие из Индивидуального плана действий на партнерство, можно ознакомиться на www.mil.am/files/IPAP-English.pdf.

4 Hayk Kotanjian, Guidelines on Developing Armenian National Security Strategy in the Context of Regional Security Architecture (Washington and Yerevan: SNSEE-INSS-NSOOC, NDU, 2004-05). 
Программы Совершенствования Образования в Сфере Обороны (ПСОСО) с участием специалистов по образованию в сфере обороны из США и НАТО. Каждая ПСОСО стремится ответить утвержденным, основанным на потребностях требованиям страны-партнера ... [в том числе и Армении]. ${ }^{5}$

Первая группа экспертов НАТО прибыла в Ереван весной 2008 года. В начале 2009 года со специалистами НАТО была согласована дорожная карта реформ в образовании в сфере обороны. Дорожная карта подчеркивала важность введения стандартов Болонского процесса в систему образования в сфере обороны с бакалаврским, магистерским и докторским уровнем; усовершенствования курсов подготовки сержантского состава; создания высших командных курсов, а в среднесрочной перспективе учреждение командной академии; учреждения межведомственного института образования в сфере обороны на стратегическом уровне, основанного на модели Национального университета обороны США путем трансформирования Армянского института национальных стратегических исследований; и введения системы дистанционного обучения в сферу военного образования.

С 2009 года армянское министерство обороны близко сотрудничает с рабочими группами Программы Совершенствования Образования в Системе Обороны НАТО. Последние три года, группа ПСОСО под академическим руководством доктора Джима Баррета часто посещала министерство обороны Армении для уточнения разных аспектов реформ системы образования в сфере обороны. Эта команда внесла свой вклад в процесс разработки курса для младших офицеров и оказала неоценимую помощь в определении целей, задач и содержания программ курса для высших офицеров, который должен начаться в 2013 году. Значительным опытом в области менеджмента стратегических реформ в системе образования рабочая группа ПСОСО располагала в большой степени благодаря участию доктора Джима Кигла из Национального университета обороны. Он внес существенный вклад в работу ПСОСО консультируя проект трансформирования армянского ИНСИ в НУО Армении, а так же предоставив опыт Командного и штабного колледжа сухопутных войск США в развитии учебных программ и повышении квалификации преподавательского состава в области принятия решений в военном деле.

Один из главных аспектов работы группы ПСОСО в Армении было ее участие в процессе разработки концепции реформ системы военного образования. В 20092011 году, группа ПСОСО близко сотрудничала с руководством министерства обороны, в том числе с министром обороны доктором Сейраном Оханяном и первым заместителем министра Давидом Тонояном.

В марте 2012 года, правительство Армении одобрило концепцию реформ системы военного образования и плана действий применения конкретных программ,

5 John Berry, "PfP Consortium of Defense Academies and Security Studies Institutes Annual Report 2011,” доступно на: www.scribd.com/doc/101738262/1/John-Berry. 
осуществляемых в рамках концепции. ${ }^{6}$ План действий предполагает реорганизацию институтов сухопутных войск и военно-воздушных сил, учреждение Командно-штабной академии и инициирование процесса трансформирования армянского Института национальных стратегических исследований в армянский НУО в 2013 году.

\section{Проект армянского НУО}

Проект армянского НУО является одним из основных столбов системы предлагаемых реформ армянской системы образования в сфере обороны, и возможно, это самый амбициозный из проектов. Армянский НУО будет учрежден путем трансформации существующего Института национальных стратегических исследований. Надо подчеркнуть, что проект армянского ИНСИ сам по себе был разработан и защищен в Академическом совете ИНСИ США в период моей работы в ИНСИ (которая была элементом моего стажа в НУО в 2002-2003 году), с намерением руководства МО в долгосрочном плане превратить его в армянский НУО по образцу НУО США. От момента создания в 2005 году, армянский ИНСИ был интеллектуальным и организационным центром для разработки двух самых важных стратегических документов: армянская Стратегия национальной безопасности и Военная доктрина Армении. ИНСИ является единственным государственным мозговым центром в Армении, занимающийся вопросами региональной безопасности и разрабатывающий секретные и несекретные политические документы со стратегическими оценками и рекомендациями для армянского военно-политического руководства. ИНСИ так же публикует два квартальных журнала - Армянская оборона, и его приложение со стратегическими исследованиями Труды ИНСИ - в котором публикуются работы экспертов и других армянских ведомств, университетов и Национальной академии наук. ИНСИ уже ввел западную культуру межведомственного сотрудничества в процесс формирования политики направляя работу межведомственной комиссии, ответственной за разработку Стратегии национальной безопасности.

Исполнительная часть проекта армянского НУО была разработана и рассмотрена во время моей исследовательской работы в рамках Программы по национальной безопасности, руководимой генерал-лейтенантом в отставке Тадом Оелстромом в школе управления им. Кеннеди при Гарвардском университете весной 2010 года. Эта программа включала и две недели обширных дискуссий и исследований в Школе права и дипломатии им. Флетчера при Университете Тафтса. Летом 2010 года проект был рассмотрен и доработан в близком сотрудничестве с экспертами Армянского государственного комитета по науке как часть целостной

6 Концепция военного образования в Армении, доступна на: https://www.e-gov.am/ u_files/file/decrees/arc_voroshum/2012/03/MAR9-18_1.pdf (на армянском). 
концепции учреждения исследовательских университетов в Армении. ${ }^{7}$ Далее проект был доведен до состояния полноценной модели исследовательского университета в Центре технологий и политики национальной безопасности в НУО США в сентябре-ноябре 2011 года под руководством доктора Джеймса Кигла.

В ноябре 2011 года, проект был представлен на специальной встрече в армянском МО с участием министра обороны и министра науки и образования, Джеймса Кигла из НУО США, высокопоставленных представителей посольства США в Ереване и международной группы экспертов ПСОСО под эгидой НАТО. ${ }^{8}$ Корригированный проект, с четкой дорожной картой, был рассмотрен на семинаре, проведенном в Ереване в июне 2012 года, в котором участвовали министр обороны, заместитель главы миссии посольства США в Ереване, и Джеймс Кигл, в качестве консультанта по академическим вопросам проекта армянского НУО. ${ }^{9}$

В январе 2013 года в армянском ИНСИ состоялась специальная рабочая встреча «Начало выполнения дорожной карты создания армянского Национального (исследовательского) университета обороны» с участием армянской и американской рабочих групп под руководством министра обороны доктора Сейрана Оханяна и министра науки и образования Республики Армения доктора Армена Ашотяна, посла США Джона Хефферна и доктора Джеймса Кигла.

Проект предполагает создание как исследовательских, так и образовательных компонентов университета, на основе идеи сочетания исследовательской и образовательной деятельностей. Исследовательский компонент будет состоять из трех центров, занимающимися исследованиями международной и региональной безопасности, кибербезопасностью и прикладными стратегическими исследованиями. Образовательный компонент будет включать два колледжа предлагающие десятимесячные магистерские программы, а так же курсы повышения квалификации продолжительностью от одного до трех месяцев для военных и гражданских сотрудников среднего и высшего уровня. Школа аспирантуры и научный совет по политическим наукам и международным отношениям ИНСИ продолжат свою работу в рамках будущего армянского НУО. Выполнение проекта НУО, направленного на инновационные изменения в межведомственной системе формирования нового поколения стратегических лидеров Армении, должно начаться в 2013 году.

7 Хайк Котанджян, «Создание стратегически ориентированной межведомственной среды: модель высшего училища в сфере обороны» (на армянском, английском и русском) работа, написанная во время работы в качестве приглашенного профессора в программе «Безопасность Евразии» в университете Гарварда, весна 2010. Смотри так же, Ethnic Policy of Conflicts. Basics of Military Policy and National Security of Armenia (Yerevan: Tigran Mets Publishing House and INSS, MoD, 2010), 723-62.

8 23-26 ноября, в рамках регулярных визитов, международная группа экспертов под эгидой инициативы НАТО ПСОСО, была в Армении чтобы оказать содействие проведению военно-образовательных реформ. Смотри www.mil.am/1322144501/page/23.

9 James Keagle and Adrian Martin, "Organizing for National Security, Unification or Coordination?," Defense Horizons 60 (December 2007), доступно на: http://www.ndu.edu/CTNSP/ docUploaded/DH_60.pdf. 


\section{Выводы}

Армянская система образования в сфере обороны претерпела огромные изменения со времени создания независимых армянских вооруженных сил двадцать лет назад. Реформы системы образования в сфере обороны начатые в середине 2000-х способствовали процессу трансформации, направленного на преодоление в основном устаревшего советского наследия и на введение современных образовательных технологий и инструментов. В этом контексте, Программа Совершенствования Образования в Сфере Обороны Консорциума ПРМ стала инновационным инструментом модернизации армянской системы профессионального военного образования, сделав его совместимым с наиболее эффективными образовательными моделями в мире и наиболее современными стандартами и технологиями взаимосвязанных процессов исследований, образования и профессиональной квалификации. 


\section{Литература}

Armenia's commitments under Individual Partnership Action Plan with NATO., 2005.

Armenia's Military Education Concept., 2012.

Berry, John. PfP Consortium of Defense Academies and Security Studies Institutes Annual Report 2011., 2011.

Decision of the Armenian government (in Armenian)., 1994.

Decision of the Armenian government., 1994.

Keagle, James, and Adrian Martin. "Organizing for National Security, Unification or Coordination?" Defense Horizons 60 (2007).

Kotanjian, Hayk. Basics of Military Policy of the Republic of Armenia: MilitaryPolitical Aspect of National Security (in Armenian). Yerevan: Military Policy Department, MOD Armenia, 1992.

Kotanjian, Hayk. Creating Strategically Oriented Interagency Environment: Senior Defense-Security School Model. Eurasia Security Program at Harvard University, 2010.

Kotanjian, Hayk. Ethnic Policy of Conflicts. Basics of Military Policy and National Security of Armenia. Yerevan: Tigran Mets Publishing House and INSS, MoD, 2010. 